\title{
Calotropis procera induced ocular toxicity, manifestations and management - an observational study
}

\author{
Pandey $\mathbf{N}^{1}$, Sahu $\mathbf{V}^{2}$ \\ ${ }^{1}$ Dr. Nidhi Pandey, Associate Professor, Department of Ophthalmology, ${ }^{2}$ Dr. Vijaya Sahu, Asosciate Professor, \\ Department of Ophthalmology. Both are affiliated to Pt. J.N.M. Medical College, Raipur, CG, India
}

Address for correspondence: Dr Nidhi Pandey, Email: nidhi_ophth@rediffmail.com

\begin{abstract}
Introduction: Calotropis procera produces copious amounts of latex, which possesses several pharmacological properties. It produces severe inflammatory response on local application and its accidental instillation in the eye is associated with significant ocular morbidity. This is an observational study to assess the ocular toxicity of the latex of Calotropis procera and its management. Methods: 34 patients presenting to the ophthalmology department of a tertiary care centre of central India with exposure to the latex of Calotropis procera, were included in the study. Results: The main symptoms reported were burning, watering and discomfort. Corneal edema with striate keratopathy was found to be a universal manifestation with or without epithelial lesions and intraocular inflammation. The keratopathy showed good response to topical corticosteroids. Conclusion: Exposure to the latex of Calotropis procera is associated with significant ocular morbidity. The typical manifestation of striate keratopathy resolves with topical steroids. Simple health education in the form of hand washing, and avoiding eye contact and eye rubbing while plucking the flowers and leaves of Calotropis can prevent this injury.
\end{abstract}

Keywords: Calotropis Procera, Keratitis, Latex, Striate Keratopathy

\section{Introduction}

Calotropis procera (Fig. 1) belonging to Asclepiadaceae family, grows as a medium branched perennial shrub or small tree. It widely grows in the tropics of Asia, Africa and Northeast of South America. In India, it grows mainly in Rajasthan, Punjab, West Bengal, Assam, Madhya Pradesh and Chhattisgarh. It grows to a height of 4-5 meters and produces copious amounts of thick milky sap which profusely exudes out on breaking the leaves or stalk of the plant. Its white or pink flowers bloom in spring. Its flowers and leaves are used to worship Lord Shiva. It is commonly known as Akra and Madaar in India and is widely used in the indigenous systems of medicine [1,2]. Ocular injuries due to mechanical trauma or accidental inoculation of the latex of Calotropis procera are not uncommon during plucking the flower or leaf stalk of the plant.

Manuscript received: $14^{\text {th }}$ Aug 2015

Reviewed: $17^{\text {th }}$ Aug 2015

Author Corrected: $27^{\text {th }}$ Aug 2015

Accepted for Publication: $8^{\text {th }}$ Sept 2015
The milky white endogenous latex, produced by the plant in appreciable amount, exhibits a variety of effects. The latex of Calotropis procera possesses numerous pharmacological properties. On oral administration, the latex produces potent antiinflammatory, analgesic, and weak antipyretic effects, while on local administration it induces an intense inflammatory response in animal model [3-6]. Proinflammatory activity seems to predominate over antiinflammatory activity, suggesting its prevalence in the whole latex. Accidental exposure to the latex has been reported to cause inflammation of the skin and eyes [2, $6,7]$. Ocular injury from this plant can be mechanical, or more commonly, toxic, due to the exposure to its latex. Since it produces severe inflammatory response on local application, its accidental instillation in the eye is associated with significant ocular morbidity. This is an observational study about the ocular toxicity of the latex of Calotropis procera and its management. 


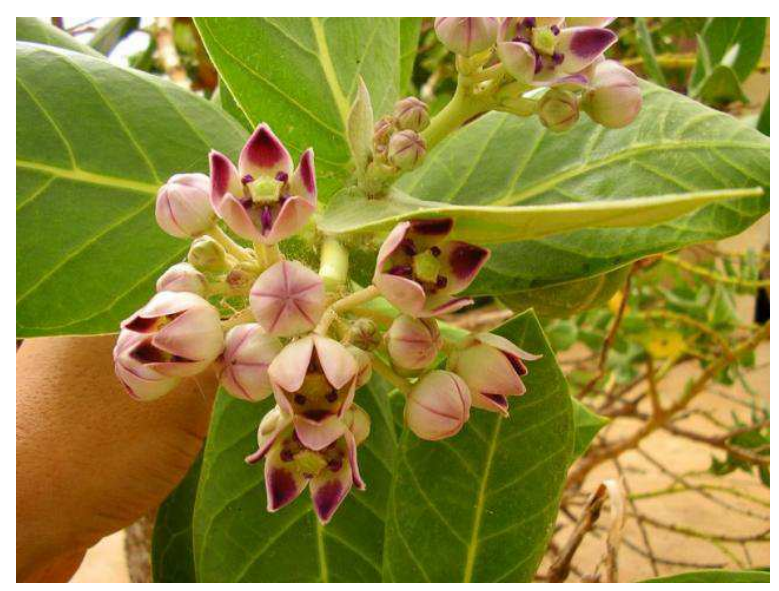

Figure- 1: Calotropis procera

\section{Material and Methods}

Patients presenting with exposure to latex of Calotropis procera to the ophthalmology department of a tertiary care hospital in central India during the period of 2005 to 2014 were included in the study. Exclusion criteria were patients having co-existing ocular co morbidities and those patients having history of any ocular surgery. A total of 34 patients were studied. An informed consent was obtained from all patients included in the study. A demographic profile and a detailed history to elicit the mode of injury were obtained from each patient. All patients underwent a complete ocular examination including best corrected visual acuity (BCVA) on presentation. Slit lamp findings, including conjunctival injection, extent of corneal involvement including fluorescein staining and intra ocular pressure measurements were recorded for each patient. All patients were called for follow up examinations regularly depending on the severity of injury and studied for all the above parameters.

\section{Results}

The age of patients ranged from 23 years to 70 years (Table 1 ). There was a strong female preponderance with $80 \%$ of the patients being females. Almost universally, the mode of injury was accidental splash of latex in eyes while plucking flowers or leaves of the plant for religious or occupational purposes. One patient inadvertently splashed the latex in his eye while applying it on his knee for arthritic pain. The involvement was unilateral in all cases. There was no history of ocular trauma, surgery, or any other ocular problem in any of the studied patients. Visual acuity was reported to be normal in all except 4 eyes before the episode. Most patients reported within 24 hours after injury (62\%).

Table 1: Demographic profile of patients

\begin{tabular}{|l|l|}
\hline Patients profile & Number of patients (\%) \\
\hline Age & $23-70$ years ( mean 40.6 \pm 8.7$)$ \\
\hline Gender Male : Female & $7: 27$ \\
\hline Right eye : Left eye & $26: 8$ \\
\hline Occupation & \\
\hline Housewives & 21 \\
\hline Flower vendors & 10 \\
\hline Priests & 3 \\
\hline Time of presentation & \\
\hline Within 24 hours & $21(62)$ \\
\hline $24-48$ hours & $10(30)$ \\
\hline After 48 hours & $3(8)$ \\
\hline
\end{tabular}


The symptoms reported were burning, associated with watering immediately after accidental splash of Calotropis latex. Symptoms of grittiness and redness followed, and within a few hours there was a noticeable blurring of vision. A mild discomfort was reported by 11 patients (32\%), while none of the patients complained of pain. (Table 2).

Table 2: Clinical feature of patients involved

\begin{tabular}{|l|l|}
\hline Clinical features & Number of patients $(\%)$ \\
\hline Chief complaints & \\
\hline Burning & $30(88)$ \\
\hline Watering & $34(100)$ \\
\hline Blurring of vision & $34(100)$ \\
\hline Discomfort (mild) & $11(32)$ \\
\hline Visual acuity on presentation(BCVA) & \\
\hline $6 / 12-6 / 6$ & $3(9)$ \\
\hline $6 / 60-6 / 18$ & $23(68)$ \\
\hline$<6 / 60$ & $8(23)$ \\
\hline Congestion & $34(100)$ \\
\hline Epithelial defect & $8(25)$ \\
\hline Corneal oedema and striate keratopathy & $34(100)$ \\
\hline Iridocyclitis & $2(5)$ \\
\hline
\end{tabular}

On examination, the visual acuity was variably reduced in all patients. Most patients (68\%) showed a moderate reduction in vision with acuity in the range of 6/60-6/18. Mild conjuctival and circumcorneal congestion was noted in all patients. Epithelial defects was present in 11 patients who had presented early (within few hours), in the rest the epithelium was intact. Corneal stroma was oedematous showing striate keratopathy in all patients. (Figure 2). The endothelium appeared normal on specular reflection. The anterior chamber was quiet with no cells or flare in all except 2 patients who showed presence of 2+ cells and flare, suggestive of iridocyclitis.. Iris, pupil and lens were also normal. Intraocular pressure was normal in all eyes (12-16 mmHg). The 3 patients who had presented late had consulted a local doctor a few hours after injury. They had been prescribed antibiotics and lubricating drops for local application. However, since there was no relief, a consultation was sought from us.

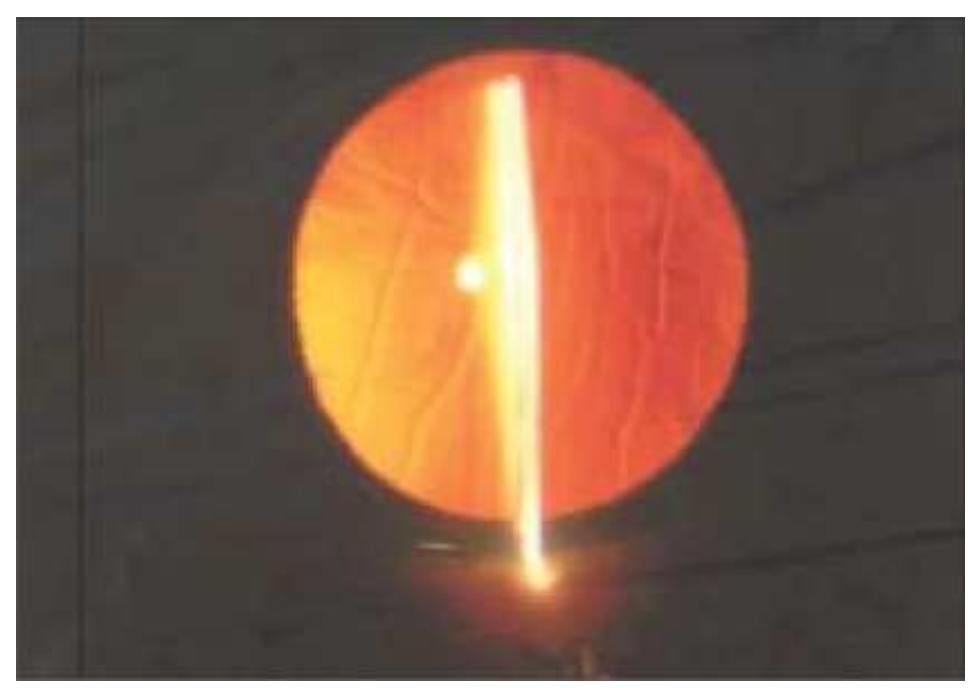

Figure 2: Slit lamp photograph showing folds in Descemtes membrane

All patients except those having epithelial defect were started topical corticosteroid eye drops (Prednisolone acetate 1\%), ranging from 4 to 6 times a day depending on the severity of corneal oedema and striate keratopathy. 
11 patients having epithelial defects were prescribed topical antibiotic drops (tobramycin 0.3\%) and lubricants (carboxy methyl cellulose $0.5 \%$ ). Resolution of epithelial defect was seen in average 4.17 days (range 2- 7 days). However, the appearance of stromal oedema and descemets membrane folds remained unchanged, and showed signs of resolution only after corticosteroid eye drops were started.

On follow up, two days after starting topical corticosteroids, the stromal oedema and striate keratitis had significantly reduced in all patients. By day 14, the inflammation had resolved completely in most eyes, with BCVA returning to normal. 31(91\%) patients showed complete resolution within one week, the mean period of resolution being $6.72 \pm 2.27$ days (range 3-14 days). The steroid drops were stopped one week after resolution. The vision returned to 6/6 in 30 patients $(88 \%)$, in the rest cornea regained a normal appearance but vision was compromised due to age related cataract.

\section{Discussion}

The latex of Calotropis procera contains several toxic compounds having irritant and pro-inflammatory properties $[4,9,10]$. The milky white latex of this plant irritates the mucous membrane and produces inflammatory reaction on local application or accidental exposure. It is known to produce contact dermatitis, and the latex of this plant produces intense inflammation when injected locally in animal models.[5,6] Shivkar et al, [6] in their study on rat paw edema model, found that the injection of dried latex produces an intense inflammatory response involving edema formation and cellular infiltration. They showed that this was due to the presence of histamine in the latex itself and also due to the release of mast cell histamine by the latex. Besides, the latex has also been shown to induce prostaglandin synthesis through the induction of cyclooxygenase -2 (COX-2) [5]. Both histamine and prostaglandins are the key mediators in any inflammatory response.

8 patients [25\%] in our study presented with epithelial defect along with stromal oedema and Descemets membrane folds. The epithelial damage may be the result of mechanical trauma due to rubbing, or due to the acid injury as suggested by Waikar et al, who found epithelial defect in $15 \%$ of their patients [11]. They have suggested the mechanism of Calotropis induced ocular manifestations to be due to two reasons, the first being the acidic nature of the milky sap and second due to the toxins present in the sap. They observed a very characteristic staining pattern in some patients in the form of inferior conjunctival staining in the pattern of a triangle with apex towards inferior limbus and base towards the fornix . They explained this to be the result of acid injury as a result of the track of a drop of sap falling into the eye, and settling down in the inferior fornix causing acid injury along its path. Basak et al found epithelial defects in $10.3 \%$ of their cases.
Absence of pain in all cases could be due to the analgesic property present in the latex of Calotropis procera [8]. Basak et al also observed a painless clinical course in all their subjects [10].

The most common presentation of exposure to Calotropis latex was stromal oedema with Descemnets membrane folds, as universally reported in other studies also $[9,10,11\}$ This may be due to inflammation induced by latex due to its strong pro-infl ammatory property resulting in endothelial toxicity. Permanent endothelial cell loss with morphological alteration was reported by Al-Mezaine et al in their case [7]. Basak et al reported low endothelial cell count in 17 out of 23 eyes $(74 \%)$ on specular microscopy at three months in comparison to the normal fellow eye [10]. Waikar et al found increased corneal thickness in affected eye as compared to the normal fellow eye on pachymetry. Specular microscopy in their cases revealed low endothelial cell count with pleomorphism and polymegathism in affected eye as compared to normal fellow eye [11]. These findings suggest that the cause of corneal oedema is endothelial toxicity. Unlike other chemical burns, the Calotropis latex is paradoxically relatively non-toxic to the corneal epithelium, but highly toxic to the corneal endothelium [10]. The resolution of keratitis with local corticosteroid use corroborates this notion.

2 patients $(5 \%)$ in our study had associated iridocyclitis. Basak et al found iridocyclitis in $9(31 \%)$ patients, while Waikar et al did not find iridocyclitis in any of their patients. Lakhtakia et al in a study of 47 patients, found 9\% with keratouveitis [12]. Toxic iridocyclitis was also reported by Tomar et al. Waikar et al explained the occurrence of iridocyclitis to be due to more quantity of sap instilled in the eye or failure to immediately wash off the sap from the eye resulting in the tracking down of toxins to anterior chamber. The 
presence of histamine and prostaglandins in the sap may the cause of iridocyclitis [11].

A noteworthy observation of our study was that the stromal oedema and Descemets membrane folds persisted until corticosteroid drops were instilled. A delay in starting steroid drops in 8 cases presenting with epithelial defects, showed persistence of these lesions till corticosteroid drops were initiated. This further supports the toxic nature of the latex.

None of our patients had secondary glaucoma, as was also observed by Waikar et al and Lakhtakia et al.[11,12] Basak et al found secondary glaucoma in $24.1 \%$ of their patients. The raised intraocular pressure could be secondary to iridocyclitis [11].

\section{Conclusion}

The latex of Calotropis procera is associated with painless blurring of vision. There is severe corneal damage manifested as stromal oedema with Descemets membrane folds with or without epithelial damage and iridocyclitis. Topical corticosteroids are the mainstay of treatment. Simple health education in the form of hand washing, and avoiding eye contact and eye rubbing while plucking the flowers and leaves of Calotropis can prevent this injury.

\section{Funding: Nil, Conflict of interest: Nil, Permission from IRB: Yes}

\section{References}

1. Mascolo N, Sharma R, Jain SC, Capasso F. Ethnopharmacology of Calotropis procera flowers. J Ethnopharmacol. 1988 Feb-Mar;22(2):211-21.

2. Tomar VP, Agarwal PK, Agarwal BL. Toxic iridocyclitis caused by Calotropis. J All India Ophthalmol Soc. 1970 Apr;18(1):15-6.

3. Arya S, Kumar VL. Antiinflammatory efficacy of extracts of latex of Calotropis procera against different mediators of inflammation. Mediators Inflamm. 2005 Aug 31;2005(4):228-32.

4. Alencar NM ${ }^{1}$, Oliveira JS, Mesquita RO et al. Proand anti-infl ammatory activities of the latex from Calotropis procera (Ait) R.Br. are triggered by compounds fractionated by dialysis. Inflamm Res. 2006 Dec;55(12):559-64.

5. Kumar VL, Shivkar MY. Involvement of prostaglandins in inflammation induced by latex of Calotropis procera. Mediators Inflamm. 2004 Jun;13(3):151-5.

6. Shivkar YM, Kumar VL. Histamine mediates the pro-inflammatory effect of latex of Calotropis procera in rats. Mediators Inflamm. 2003 Oct;12(5):299-302.

7. Al-Mezaine HS, Al-Rajhi AA, Al-Assiri A, Wagoner MD. Calotropis procera (ushaar) keratitis. Am J Ophthalmol. 2005 Jan;139(1):199-202.

8. Dewan S,Sangraula H, Kumar VL. Preliminary studies on the analgesic activity of Calotropis procera. $\mathbf{J}$ Ethnopharmacol. 2000 Nov;73(1-2):307-11.

9. Pandey N, Chandraker AK, Garg ML, Patel SS. Calotropis procera induced keratitis. Indian $\mathbf{J}$ Ophthalmol. 2009 Jan-Feb;57(1):58-60.

10. Basak SK, Bhaumik A, Mohanta A, Singhal P. Ocular toxicity by latex of Calotropis procera . Indian J Ophthalmol. 2009 May-Jun;57(3):232-4. doi: 10.4103/0301-4738.49402.

11. Waikar S, Srivastava VK. Calotropis induced ocular toxicity. Med J Armed Forces India. 2015 Jan;71(1):924. doi: 10.1016/j.mjafi.2012.08.017. Epub 2012 Oct 23.

12. Lakhtakia S, Dwivedi PC, Choudhary P, Chalisgaonkar C, Rahud J. Ocular toxicity of Calotropis- missing links. Indian J Ophthalmol. 2010 Mar-Apr;58(2):169; author reply 169 . doi: 10.4103/0301-4738.60074.

\section{How to cite this article?}

Pandey N, Sahu V. Calotropis procera induced ocular toxicity, manifestations and management - an observational study. Int J Med Res Rev 2015;3(8):805-809. doi: 10.17511/ijmrr.2015.i8.151. 